\title{
Commercial scale production of inorganic nanoparticles
}

\author{
Takuya Tsuzuki \\ Centre for Material and Fibre Innovation, \\ Deakin University, \\ Geelong Technology Precinct, \\ Geelong, VIC 3217, Australia \\ Fax: +61352252539_E-mail: takuya@deakin.edu.au
}

\begin{abstract}
This review focuses on the current trend in the commercial scale production methods of inorganic nanoparticles. The limiting factors for the scalability of synthesis methods are explained and the relationship between commercial nanoparticle materials and production methods is discussed. Particular emphasis is placed on the fact that different synthesis techniques lead to different properties of nanoparticles even when the qualities such as particle size and crystal phase appear quite similar. The production techniques of nanoparticles need to be carefully selected based not only on the scalability and production costs, but also on the properties of nanoparticles required for specific applications.
\end{abstract}

Keywords: nanoparticles; applications; synthesis methods; large scale production.

Reference to this paper should be made as follows: Tsuzuki, T. (2009) 'Commercial scale production of inorganic nanoparticles', Int. J. Nanotechnol., Vol. 6, Nos. 5/6, pp.567-578.

Biographical notes: Takuya Tsuzuki received a $\mathrm{PhD}$ in Condensed Matter Physics from Kyoto University, Japan and a Graduate Certificate in Technology Management from La Trobe University, Australia. He has over 15 years of research experience in the synthesis of nano-powders and physical/chemical characterisation of nanoparticulate materials. In 2004, he was nominated as one of top publishing nanotechnology authors in Australia by the Australian Academy of Science. In his last position as the Chief Technology Officer of a nanotechnology company, he was responsible for the development of large scale production of metal oxide nanoparticles and their commercial applications. He is currently a Senior Research Academic of the Centre for Material and Fibre Innovation, Deakin University, Australia. He has five PCT patents and has (co-)authored over 60 refereed publications in international journals and proceedings.

\section{Introduction}

Nanoparticles are a new class of materials [1-3]. They are less than $\sim 100 \mathrm{~nm}$ in diameter and exhibit new or enhanced size-dependent properties compared with larger particles of the same material. The ability to fabricate and control the structure of nanoparticles 
allows scientists and engineers to influence the resulting properties and, ultimately, design materials to give the desired properties. The current and potential applications for nanoparticles are growing and cover an extremely broad range of markets and industries including biomedical and cancer treatment, renewable energy, environmental protection, pharmaceuticals, personal care, surface coatings, plastics, textiles, food, building materials, electronics, automotives, etc. (Figure 1).

Like other fields of nanotechnology, applications of nanoparticles offer much promise to improve and enrich our daily life [4,5]. In fact, there are already a number of nanoparticle-based consumer products available on the market [5]. For example, personal care products containing $\mathrm{TiO}_{2}$ and $\mathrm{ZnO}$ nanoparticles are sold extensively to protect human skin from harsh UV rays. Silver nanoparticles are used as an antibacterial agent in many consumables ranging from surgical instruments to door knobs. Woodrow Wilson International Centre for Scholars, Projects on Emerging Nanotechnology, counted nanomaterial-based consumer goods in October 2007 to be 580 and the number is increasing with an extraordinary speed [6].

Figure 1 Major application of nanoparticles (see online version for colours)

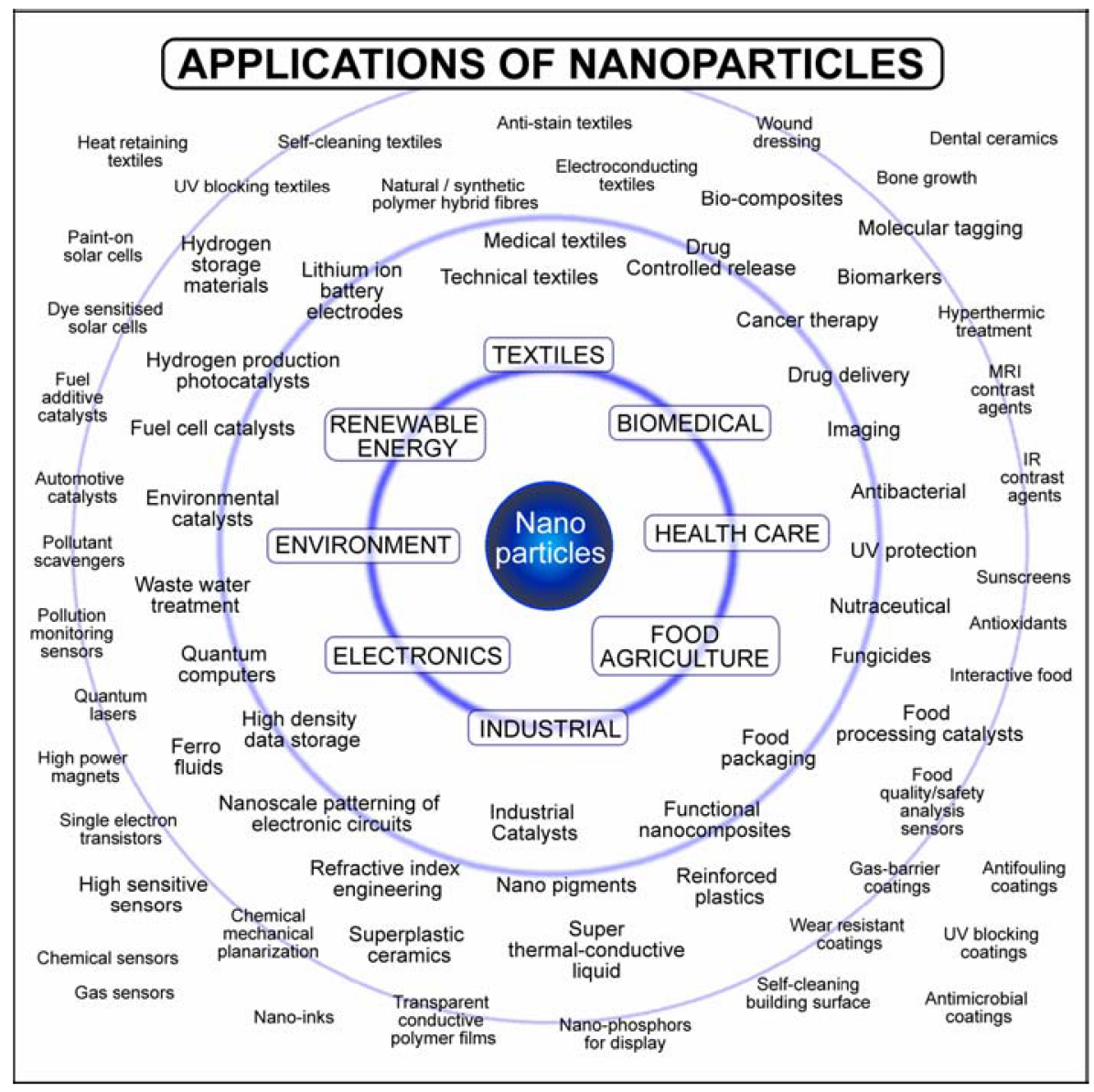


However, most of those applications are based on only a few nanoparticle materials such as silver, gold, silica, alumina, fullerenes, titanium oxide and zinc oxide. Many other nanoparticulate materials that show unique and useful properties still remain on the laboratory bench. There are many reasons for the slow progress in bringing innovation from laboratories to end-products. One of the most prominent obstacles for the commercial application of nanoparticles is the lack of development of large scale production. In 2002, Holister and Harper predicted that, the four major markets for nanoparticles by volume are automotive catalysts (11,500 tonnes), chemical mechanical planarisation slurry $(9,400$ tonnes), magnetic recording media (3,100 tonnes) and sunscreens (1,500 tonnes) [7]. Although the required volume of nanoparticles varies from application to application, in general, nanoparticle production in a similar scale to those is required to take nanotechnology innovation to ordinary people's life.

This short review discusses the current trends in the commercial scale production methods of inorganic nanoparticles. Some fundamental aspects of production development are also briefly described to assist academic researchers who plan to take their research outcomes into the market. Although carbon-related nanoparticles are included in the discussion, organic nanoparticle materials are outside of the scope of this review.

\section{Overview of the methods used for commercial scale production}

In the last two decades, significant research efforts have been made to develop methods for nanoparticle synthesis [2,8-10]. As a result, a considerable number of techniques are currently used in laboratories world wide (Table 1). For example, Willams and Van den Wildenburg listed more than 20 laboratory scale techniques that are commonly known to researchers [5]. However, the yield of most of the laboratory scale synthesis is around $1 \mathrm{~g}$ per batch. Although $10-100 \mathrm{~g}$ per batch is sometimes possible and is regarded as large scale synthesis in the laboratory, such amount is far less than the quantity required for commercial scale production.

Currently there are over 100 commercial companies that produce large quantities of inorganic nanoparticles [11]. In order to study the trend in the commercial scale production methods, 100 companies were randomly selected and the techniques they use were determined. The selected companies range from large multinational corporations to small start-ups. Figure 2 shows the statistics of the production methods the commercial nanoparticle companies use. Since many companies do not explicitly describe the detailed method they use, the methods were divided into five generic categories, namely, comminution (mechanical grinding/milling), vapour, liquid and solid phase techniques and the combinations of those.

As shown in Figure 2, the majority of the selected companies use either vapour phase synthesis $(43 \%)$ or liquid phase synthesis $(42 \%)$ techniques. However, the popularity of particular methods does not directly translate into the superiority or versatility of the techniques. Many companies choose production techniques due to historical reasons or accessibility to raw materials for the production of a certain type of nanoparticles. The reason why there is only one company operating using a solid-phase bottom-up synthesis technique is due to the fact that the company processes a strong patent which covers most of the aspects of the production technology 
(mechanochemical process) and hence no other company can use the same production method.

Table 1 Techniques used for laboratory scale synthesis of inorganic nanoparticles

\begin{tabular}{|c|c|c|}
\hline Approach & $\begin{array}{l}\text { Synthesis } \\
\text { environment }\end{array}$ & Methods \\
\hline $\begin{array}{l}\text { Top down } \\
\text { approach }\end{array}$ & & Mechanical grinding/milling (dry, wet) \\
\hline \multirow[t]{3}{*}{$\begin{array}{l}\text { Bottom up } \\
\text { approach }\end{array}$} & $\begin{array}{l}\text { Vapour phase } \\
\text { synthesis }\end{array}$ & $\begin{array}{l}\text { Physical vapour deposition, chemical vapour deposition, } \\
\text { flame pyrolysis, spray pyrolysis, laser ablation, plasma, } \\
\text { gas condensation, electro-explosion, electro-splaying, } \\
\text { cluster-beam, etc. }\end{array}$ \\
\hline & $\begin{array}{l}\text { Liquid phase } \\
\text { synthesis }\end{array}$ & $\begin{array}{l}\text { Sol-gel, hydrothermal, solvothermal, sonochemical, reverse- } \\
\text { micelle, colloids, biological, electro deposition, microwave, etc. }\end{array}$ \\
\hline & $\begin{array}{l}\text { Solid phase } \\
\text { synthesis }\end{array}$ & Mechanochemical processing, Thermo-mechanical processing \\
\hline
\end{tabular}

Figure 2 Techniques used for commercial scale production of inorganic nanoparticles. Top-down and bottom-up approaches are indicated in red and blue fonts, respectively (see online version for colours)

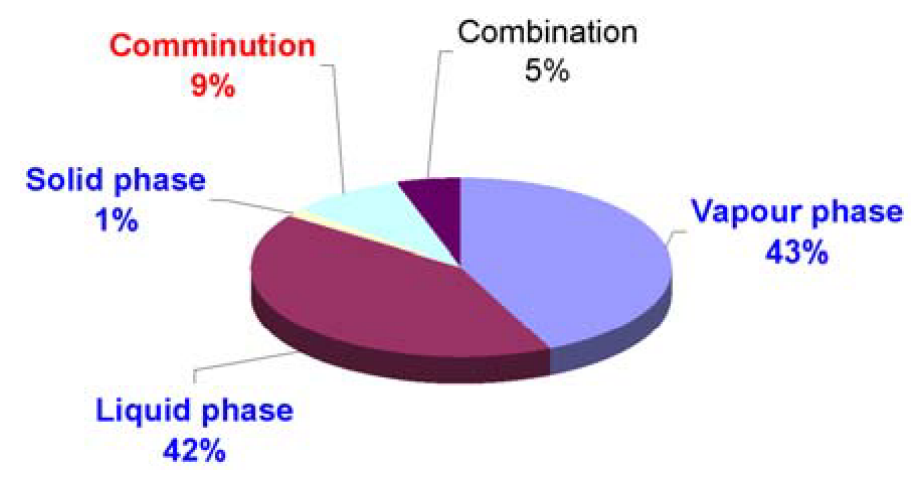

Table 2 shows the relationship between the groups of nanoparticulate material products and their large scale production techniques used by the 100 commercial nanoparticle companies. On a laboratory scale, all the five production techniques listed in Table 2 are potentially capable of producing most of the material in those groups. For example, it is demonstrated that mechanochemical and thermo-mechanical processes can produce metals, nitrides, semiconductor quantum dots and metal oxide nanoparticles [12]. However, on a commercial scale, a certain technique is used to produce only selected materials.

The reason is mainly due to the fundamental capability of the technique to produce certain materials in a large scale. When commercialisation is concerned, however, not only production capacity but other factors need to be considered. Those factors include consistency in product quality and costs related with raw materials, operation, yield, capital equipment, safety, waste disposal and environmental issues such as carbon emission. Therefore, scalability of the production method is a necessary but not a sufficient condition for the commercialisation of nanotechnology innovation. 
Table 2 Relationship between commercial inorganic nanoparticle products and production methods

\begin{tabular}{lcccc}
\hline & \multicolumn{2}{c}{ Top-down } & \multicolumn{3}{c}{ Bottom-up } \\
\cline { 2 - 5 } Products & $\begin{array}{c}\text { Mechanical } \\
\text { grinding }\end{array}$ & $\begin{array}{c}\text { Solid phase } \\
\text { synthesis }\end{array}$ & $\begin{array}{c}\text { Liquid phase } \\
\text { synthesis }\end{array}$ & $\begin{array}{c}\text { Vapour phase } \\
\text { synthesis }\end{array}$ \\
\hline Metals (excluding silver and gold) & & & $\sqrt{ }$ & $\sqrt{ }$ \\
Silver, gold & & & $(\sqrt{ })$ \\
Carbides, nitrides & & & $\sqrt{ }$ \\
Carbon (CNT, C60, diamond) & $\sqrt{ }$ & $\sqrt{ }$ & $\sqrt{ }$ & $\sqrt{ }$ \\
Semiconductor quantum dots & & & & $\sqrt{ }$ \\
Metal oxides & & & & \\
\hline
\end{tabular}

For example, materials that are reactive to oxygen and moisture, such as non-precious metals, are commercially produced using only vapour phase methods due to the ease of scale-up under a tight quality control. Silver and gold are almost exclusively produced using liquid-phase precipitation methods to take advantage of inexpensive raw materials and ease of control of particle sizes. Carbides, nitrides and carbon-related materials often require high crystallinity and hence demand the use of high temperature synthesis that is one of the strengths of vapour phase synthesis techniques. For semiconductor quantum dots, stoichiometry and crystalline phases need to be precisely controlled to obtain desired quantum effects, which liquid-phase synthesis is most suitable for.

The reason why only a few types of nanoparticulate materials are used in the current consumer products is due to those technical and commercial restrictions on large scale production. In order to introduce a wider variety of nanoparticle materials to the market to expand application areas, it is necessary to further improve the existing methods and to develop new synthesis techniques with scalability and commercial viability in mind.

If the research is focused on practical applications instead of fundamental science, it may be useful to use commercial nanoparticle products that are already available on the market, instead of using nanoparticles synthesised by special techniques unsuitable for large scale production. This is particularly the case where the properties of nanoparticles depend on the synthesis methods even if average particle sizes are similar, as will be discussed in the next section.

\section{Properties that depend on synthesis methods}

In order to elucidate the effects of synthesis methods on the properties of nanoparticle products, we first review the advantages and disadvantages of the techniques used for commercial production, with a special focus on metal oxides and scalability, then discuss the difference in properties of $\mathrm{ZnO}$ nanoparticles that were produced using different techniques. 


\subsection{Mechanical grinding/milling (top-down)}

Top-down approach is an extension of traditional methods to produce large quantities of fine and/or nanocrystalline powders. These processes generally involve high energy dry/wet milling, with the addition of milling aids, and typically use milling times from several hours up to many days [13-17]. The advantages include relatively simple operation, ease of scalability and convenience to form slurries in various liquid matrices. In recent years, much improvement was made on the milling instruments and the quality of grinding media in $<0.1 \mathrm{~mm}$ diameter range, which has led to significant progress in the use of this technique for the production of a wide range of metal oxide nanoparticles. However, the top-down approach still suffers from difficulties in ensuring that all the particles are milled properly. This disadvantage becomes more serious as the hardness of metal oxide materials increases. The drawback typically results in a wide particle size distribution having a long 'tail' on the larger particle side, representing the un-milled precursors in the final commercial products. In addition, longer milling times will result in more milling impurities. The removal of these impurities, and/or any grinding aids which were used in the processing can cause subsequent problems.

\subsection{Vapour phase technique (bottom-up)}

Vapour phase techniques create nanoparticles by the rapid solidification of a liquid or vapour in a gaseous medium $[18,19]$. This has been achieved by methods ranging from burning precursors to more elaborate vapourisation or plasma-based synthesis methods. Particle size, agglomeration and size distribution are controlled by the vaporisation rate and the flow of the newly formed particles. Since the melting temperature of metal oxides are normally extremely high, corresponding metals are often used as the precursors which are vapourised using resistance, electron beam, laser or electric arc at a temperature beyond the melting point of the material, until a sufficient rate of atomisation is achieved.

The technique is advantageous for producing metal oxide nanoparticles with high purity and high crystallinity, due to the fewer sources of contaminants and the high temperatures involved. However, the method suffers from the inevitable trade-off between particle size/quality and throughput. Increasing production rates will make it increasingly difficult to control particle growth and to prevent agglomeration, due to high temperature operations and lack of a solid medium that hinders agglomeration. Normally the resulting nanoparticles in commercial scale production have characteristics of high crystallinity, geometrical shapes, a wide size distribution and evidence of agglomeration or particle sintering.

\subsection{Liquid phase technique (bottom-up)}

Liquid phase processes have been widely used in industry to make conventional micron-scale powders, and have proven to be economical for many materials. The advantages are the ability to control particles sizes, shapes and stoichiometry in a precise manner, as well as flexibility in reaction paths. To date, the smallest commercial nanoparticles such as quantum dots are produced using liquid phase techniques. Most of the recent developments on the technique have revolved around improvement of the stability of an inherently unstable system, by the use of 
various polymers, vesicles, gels or microemulsions that constrain the growth of the particles [20-22]. Additional process to remove those additives is normally required.

However, the difficulty in scaling-up the production lies in achieving stable and uniform reaction environment in large chemical baths to ensure uniform quality of the resulting nanoparticles. Increase in production rate requires high particle concentration which causes particle agglomeration during particle growth. Moreover, the resulting particles are often hydroxides or other types of salts and hence additional processes to decompose the salts into oxides are necessary, which introduces the chance of particle sintering. As a result, nanoparticles in commercial scale production have characteristics of spherical shapes, a narrow size distribution of primary particles but high degrees of agglomeration.

Due to the chance of agglomeration that is inherent to vapour and liquid phase methods, mechanical grinding is often employed at the final production stage of those nanoparticles.

\subsection{Solid phase technique; mechanochemical processing (bottom-up)}

The technology uses high energy dry milling to mechanically induce chemical reactions to occur at low temperature in a ball mill [13,14,23-25]. Milling of precursor powders leads to the formation of a nanoscale composite structure of the starting materials which react during milling or subsequent heat treatment to precipitate nanoparticles of the desired phase within a solid matrix. By carefully controlling the volume ratio between nanoparticle and salt matrix phases, the precipitated nanoparticles can be separated from each other by the solid matrix. The nanoparticles can be further heat treated in the solid matrix that prevents temperature-induced agglomeration from occurring. Then the nanoparticles are collected simply by selective removal of the matrix phase [12,26].

The technique has advantages such as relatively simple operation and ease to create uniform reaction environment that leads to uniform size and shape of nanoparticles. Of significance is the fact that this technique allows the formation of nanoparticles separated by a solid matrix during particle growth stage, leading to agglomeration-free nanoparticles. However, additional processes to remove the solid-matrix and by-product phases increase production costs and chance of contamination. The characteristics of mechanochemically produced nanoparticles are near-spherical shapes, a very narrow size distribution and low levels of agglomeration.

\subsection{Example: $\mathrm{ZnO}$ nanoparticles}

Dodd et al. [27] and Tsuzuki et al. [28] have investigated the properties of $\mathrm{ZnO}$ nanoparticles that are synthesised using solid, liquid and vapour phase syntheses. In the study, commercial $\mathrm{ZnO}$ nanoparticles that were made using liquid and vapour phase syntheses were compared with $\mathrm{ZnO}$ nanoparticles synthesised in the laboratory using mechanochemical processing [29].

The particle sizes of those three nanoparticle samples were measured by different methods. Crystallite size was estimated from the full-width half-maximum breadth of the diffraction peaks using the Scherrer equation. The average particle diameter (BET particle size) was estimated from the Brunauer-Emmett-Teller specific surface area through $D=6 / S \rho$, where $D$ is the average particle diameter, $S$ is the specific surface 
area, and $\rho$ is the density $5.61 \mathrm{~g} / \mathrm{cm}^{3}$. Number weighted particle size was also measured by photo correlation spectroscopy (PCS).

As shown in Table 3, there was a wide variation between the average particle sizes measured by these different techniques. In fact, the variation between sizes of different definitions is a convenient measure to estimate the degree of agglomeration [30]. Better agreement between different sizing methods indicates less degrees of agglomeration. The results in Table 3 shows that the degree of agglomeration in the mechanochemically synthesised nanoparticles was less than that for commercial nanoparticles produced using liquid and vapour methods.

Table 3 Particle sizes of $\mathrm{ZnO}$ nanoparticles synthesised using different techniques [28]. Particle sizes were estimated from specific surface are, X-ray diffraction peak width and dynamic light scattering

\begin{tabular}{lcccc}
\hline Synthesis methods & $\begin{array}{c}\text { BET surface } \\
\text { area }\left(\mathrm{m}^{2} / \mathrm{g}\right)\end{array}$ & $\begin{array}{c}\text { BET particle } \\
\text { size }(\mathrm{nm})\end{array}$ & $\begin{array}{c}\text { Crystallite } \\
\text { size }(\mathrm{nm})\end{array}$ & $\begin{array}{c}\text { PCS particle } \\
\text { size }(\mathrm{nm})\end{array}$ \\
\hline Solid phase method & 41 & 26 & 24 & 24 \\
Liquid phase method & 41 & 26 & 20 & 160 \\
Vapour phase method & 14 & 77 & 50 & 170 \\
\hline
\end{tabular}

For all the three samples, at least one sizing method gave average particle sizes between $20-50 \mathrm{~nm}$. Hence, depending on the sizing methods chosen, the product specification sheets of the three samples may appear similar to each other in terms of average particle size. And yet, the agglomeration states vary largely. Since there is no guideline or regulation on the definition of particle size currently applied to commercial nanoparticles [31], it is recommended that the users of commercial nanoparticles employ more than one sizing methods to assess the quality of nanoparticle products.

Figure 3 shows the UV-Vis specular transmission spectra of $\mathrm{ZnO}$ nanoparticle suspensions. In the visible light region, the nanoparticles synthesised using the solid-phase method exhibits the highest transparency, which is attributable to the fine particle size, narrow size distribution and a high degree of dispersion that were achieved due to the particle separation by a solid matrix [12]. Although the nanoparticles produced using a liquid phase method had small crystallite sizes, the optical transparency was significantly lower, due to the presence of agglomeration of $\sim 160 \mathrm{~nm}$ in size as measured by photo correlation spectroscopy (Table 3). The nanoparticles produced using a vapour phase method showed the lowest transmission in the visible wavelength region as a consequence of their significantly larger crystallite and agglomerate sizes. Therefore, for the application of transparent UV-screening nanocomposite films, commercial $\mathrm{ZnO}$ nanoparticles that are produced using a solid phase technique are more suitable.

Figure 4 shows the photoluminescence spectra of aqueous $\mathrm{ZnO}$ suspensions. The photoluminescence was weak for the nanoparticles synthesised using solid and liquid phase methods. In contrast, the nanoparticles produced using a vapour phase method gave comparatively strong emission. In general, the intensity of photoluminescence improves as the crystallinity increases. Due to the high temperature involved in the process, vapour phase techniques tend to produce nanoparticles having high crystallinity. Hence, for the applications involving photoluminescence, commercial $\mathrm{ZnO}$ nanoparticles that are produced using a vapour phase technique are more advantageous. 
Figure 3 Synthesis-method dependence of the UV-Vis specular transmission spectra of $\mathrm{ZnO}$ nanoparticle suspensions in deionised water, at the particle concentration of $0.01 \mathrm{wt} \%$ and the optical path length of $10 \mathrm{~mm}$. Polyacrylic electrolyte was added $10 \mathrm{wt} \%$ relative to $\mathrm{ZnO}$. Prior to measurement, the suspensions were subjected to intense ultrasonication for $15 \mathrm{~min}$ [28] (see online version for colours)

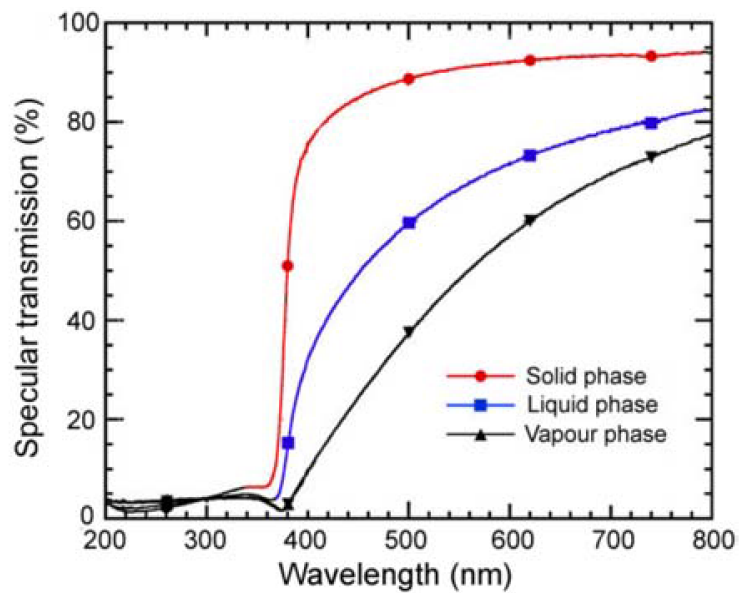

Figure 4 Synthesis-method dependence of the photoluminescence spectra of $\mathrm{ZnO}$ nanoparticle suspensions in deionised water [27] (see online version for colours)

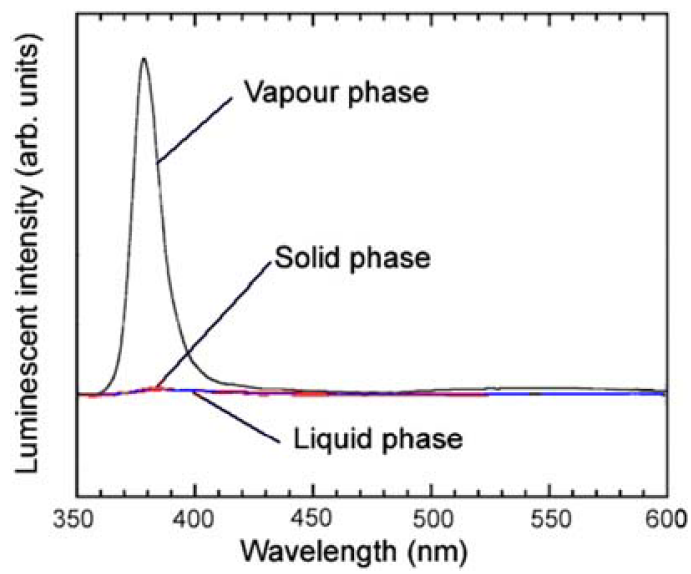

The photocatalytic activity of the nanoparticles was characterised by measuring the hydroxyl radical concentration using a spin-trapping technique with electron paramagnetic resonance (EPR) spectroscopy [32]. A solution of 5,5-dimethyl-1-pyrroline $\mathrm{N}$-oxide (DMPO) spin-trap was added to the aqueous suspension of the nanoparticles and the intensity of the first derivative EPR spectrum corresponding to the DMPO-OH spin adduct was measured upon UV light irradiation.

Figure 5 shows the DMPO-OH yield of $\mathrm{ZnO}$ nanoparticles normalised against the specific surface area [27]. It is evident that the powders synthesised using a vapour phase method exhibit significantly higher levels of photocatalytic activity per unit of surface area than the nanoparticles prepared by solid and liquid phase methods. The lower crystallinity in the nanoparticles prepared by solid and liquid phase 
methods promoted recombination of photo-generated charges which led to suppressed $\mathrm{OH}$ radical generation. Hence, for applications based on photocatalysis, commercial $\mathrm{ZnO}$ nanoparticles that are produced using vapour phase techniques are preferable. For applications such as personal care or nanocomposites where less photoactivity is required, commercial $\mathrm{ZnO}$ nanoparticles produced using solid or liquid phase technique should be considered.

Figure 5 Synthesis-method dependence of the surface area normalised photocatalytic activity of $\mathrm{ZnO}$ nanoparticle suspensions in deionised water [27] (see online version for colours)

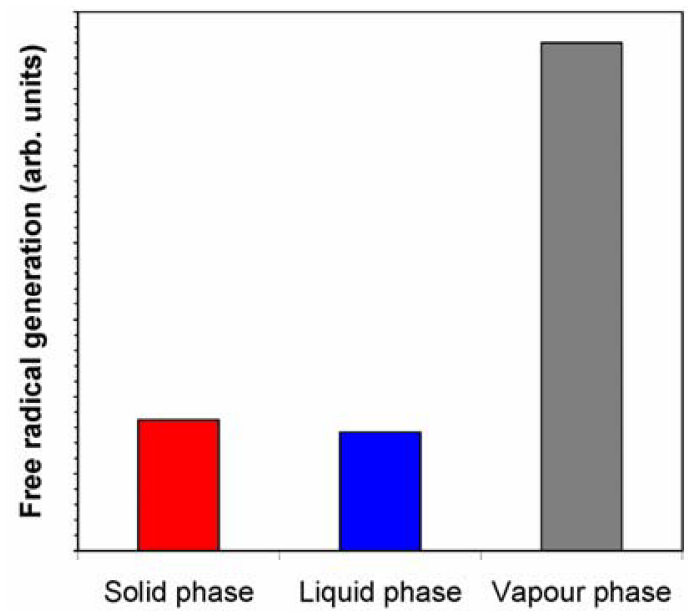

\section{Summary}

Nanoparticles promise significant improvement to our life and environment in many ways. Extensive research activities are on-going world wide to study the fundamental properties of nanoparticles and their practical applications. In order to take such useful innovation to ordinary people's life, large scale production of high quality nanoparticles is necessary. Although a multitude of different production methods is available on a laboratory scale, only a few methods are currently used for commercial scale production and each method has a limited range of nanoparticle materials it can produce in a commercially viable manner. Of particular significance is the fact that each production method results in nanoparticles having a unique combination of properties; different methods lead to different properties of nanoparticles. Even when the qualities such as particle size and crystal phase appear quite similar on a specification sheet of those nanoparticle products, some properties that are critical to specific applications may vary largely, depending on the production techniques used. For research works on the specific applications of nanoparticles, it is important to select synthesis techniques based on the properties required for targeted applications as well as on the scalability of the technique. 


\section{Acknowledgements}

A part of this work was supported by Advanced Nanotechnology Limited and the Australian Research Council under Linkage Project LP0349177.

\section{References and notes}

1 Pitkethly, M.J. (2003) 'Nanoparticles as building blocks?', Nano Today, December, pp.36-42.

2 Hosokawa, M., Nogi, K., Naito, M. and Yokoyama, T. (2007) Nanoparticle Technology Handbook, Elsevier, Amsterdam, Netherlands.

3 Roco, M.C. (1999) 'Nanoparticles and nanotechnology research', J. Nanopart. Res., Vol. 1, No. 1, pp.1-6.

4 BCC research (2006) Nanoparticle Industry Review 2005.

5 Perez, J., Bax, L. and Escolano, C. (2005) Roadmap Report on Nanoparticles, Willems \& van den Wildenberg, Spain.

$6 \mathrm{http} / /$ www.nanotechproject.org/inventories/consumer/analysis_draft/, (accessed March 2008)

7 Holister, P. and Harper, T.E. (2002) The Nanotechnology Opportunity Report, CMP Cientificia, Nos. 1 and 2, March.

8 Masala, O. and Seshadri, R. (2004) 'Synthesis routes for large volumes of nanoparticles', Annu. Rev. Mater. Res., Vol. 34, pp.41-81.

9 Rao, C.N.R. and Cheetham, A.K. (2006) The Chemistry of Nanomaterials: Synthesis, Properties and Applications, Wiley-VCH.

10 Baraton, M.I. (2002) Synthesis, Functionalization and Surface Treatment of Nanoparticles, American Scientific Publishers, Stevenson Ranch, CA, USA.

$11 \mathrm{http} / / / w w w . n a n o v i p . c o m /$ (accessed March 2008)

12 Tsuzuki, T. and McCormick, P.G. (2004) 'Mechanochemical synthesis of nanoparticles', J. Mater. Sci., Vol. 39, pp.5143-5149.

13 Miami, F. and Maurigh, F. (2004) 'Mechanosynthesis of nanophase powders', in Schwarz, J.A., Contescu, C.I. and Putyera, K. (Eds.): Dekker Encyclopedia of Nanoscience and Nanotechnology, CRC Press, Vol. 2, pp.1787-1796, Boca Raton, FL, USA.

14 Zhang, D.L. (2004) 'Processing of advanced materials using high-energy mechanical milling', Prog. Mater. Sci., Vol. 49, pp.537-560.

15 Koch, C.C. (2003) 'Top down synthesis of nanostructured materials; mechanical and thermal processing methods', Rev. Adv. Mater. Sci., Vol. 5, pp.91-99, ISSN 1606-5131.

16 De Castro, C.L. and Mitchell, B.S. (2002) 'Nanoparticles from mechanical attrition', in Baraton, M.I. (Ed.): Synthesis, Functionalization and Surface Treatment of Nanoparticles, , American Scientific Publishers Chap. 1, pp.1-15, Stevenson Ranch, CA, USA.

17 Suranarayana, C. (2001) 'Mechanical alloying and milling', Prog. Mater. Sci., Vol. 46, pp.1-184.

18 Granqvist, C.G., Kish, L.B. and Marlow, W.H. (2004) Gas Phase Nanoparticle Synthesis, Springer, Dordrecht, Netherlands.

19 Kruis, F.E., Fissan, H. and Peled, A. (1998) 'Synthesis of nanoparticles in the gas phase for electronic, optical and magnetic applications - a review', J. Aerosol Sci., Vol. 29, Nos. 5-6, pp.511-535.

20 Vayssieres, L. (2004) 'On the design of advanced metal oxide nanomaterials', Int. J. Nanotechnology, Vol. 1, Nos. 1-2, pp.1-41.

21 Park, J., Joo, J., Kwon, S.G., Jang, Y. and Hyeon, T. (2007) 'Synthesis of monodisperse pherical nanocrystals', Angew. Chem. Int. Ed., Vol. 46, pp.4630-4660. 
22 Eastoe, J., Hollamby, M.J. and Hudson, L. (2006) 'Recent advances in nanoparticle synthesis with reversed micelles', Adv. Colloid Interface Sci., Vols. 128-130, pp.5-15.

23 Senna, M. (2001) 'Recent development of materials design through a mechanochemical route', Int. J. Inorg. Mater., Vol. 3, pp.509-514.

24 Boldyrev, V.V. (1996) 'Mechanochemistry and mechanical activation', Mater. Sci. Forum, Vols. 225-227, pp.511-520.

25 McCormick, P.G. (1995) 'Application of mechanical alloying to chemical refining', Mater. Trans., JIM, Vol. 36, No. 2, pp.161-169.

26 Urakaev, F.K.H., Shevchenko, V.S. and Boldyrev, V.V. (2005) 'Theoretical and experimental investigation of mechanosynthesis of nanoparticles by means of dilution with the final product', Chem. Sustainable Dev., Vol. 13, No. 2, pp.321-337.

27 Dodd, A., McKinley, A., Tsuzuki, T. and Saunders, M. (2008) 'A comparative evaluation of the photocatalytic and optical properties of nanoparticulate $\mathrm{ZnO}$ synthesised by mechanochemical processing', J. Nanopart. Res., published on line 13 June 2008, DOI 10.1007/s11051-008-9412-1.

28 Tsuzuki, T., Innes, B., Dawkins, H., Dunlop, J., Trotter, G., Nearn, M. and McCormick, P.G. (2002) 'Nanotechnology and the cosmetic chemist', NutraCos, Vol. 1, No. 5, pp.7-12.

29 Tsuzuki, T. and McCormick, P.G. (2001) 'ZnO nanoparticles synthesised by mechanochemical processing', Scripta Mater., Vol. 44, Nos. 8-9, pp.1731-1734.

30 Tsuzuki, T. and McCormick, P.G. (2001) 'Synthesis of ultrafine ceria powders by mechanochemical processing', J. Am. Ceram. Soc., Vol. 84, No. 7, pp.1453-1458.

31 International Organisation for Standarization (ISO) Technical Committee (TC) 229 on nanotechnologies, working group two on terminology and nomenclature; measurement and characteristion has been actively working as the cross-sector coordinating body for the purposes of facilitating the development of standards in the area of nomenclature/terminology and testing, measurement and characterization procedures since 2005.

32 Grela, M., Coronel, M. and Colussi, A.J. (1996) 'Quantitative spin-trapping studies of weakly illuminated titanium dioxide sols. Implications of the mechanism of photocatalysis', J. Phys. Chem., Vol. 100, pp.16940-16946. 